\title{
Two-Stage, Input-Specific Synaptic Maturation in a Nucleus Essential for Vocal Production in the Zebra Finch
}

\author{
Laura L. Stark and David J. Perkel \\ Department of Neuroscience, University of Pennsylvania, Philadelphia, Pennsylvania 19104
}

In most songbirds, vocal learning occurs through two experience-dependent phases, culminating in a reduction of behavioral plasticity called song crystallization. At ends of developmentally plastic periods in other systems, synaptic properties change in a fashion appropriate to limit plasticity. Maturation of glutamatergic synapses often involves a reduction in duration of NMDA receptor (NMDAR)-mediated synaptic responses and a coincident reduction in the contribution of NMDARs to synaptic transmission. We hypothesized that similar changes in the zebra finch song system help limit behavioral plasticity during song development. Nucleus robustus archistriatalis (RA) is a key nucleus in the forebrain song motor pathway and receives glutamatergic input from the motor nucleus HVc. RA also receives glutamatergic input, mediated primarily by NMDARs, from the lateral magnocellular nucleus of the anterior neostriatum, which is part of a circuit essential for

Many neural systems undergo periods of activity-dependent developmental plasticity during which key connections are formed, refined, or eliminated (Constantine-Paton et al., 1990; Katz and Shatz, 1996). Often, ends of plastic periods are accompanied by changes in physiological properties of synapses, termed synaptic maturation (Fox and Zahs, 1994; Hofer and Constantine-Paton, 1994). In the CNS, two changes in glutamatergic synaptic transmission typically coincide during synaptic maturation: responses mediated by NMDA receptors (NMDARs) become more rapid, and their contribution to the synaptic response lessens compared with that made by AMPA receptors (AMPARs) (Carmignoto and Vicini, 1992; Hestrin, 1992; Crair and Malenka, 1995; Wu et al., 1996). Because activation of NMDARs is necessary for several types of neural plasticity, these two changes may combine to reduce the degree to which plasticity occurs.

We hypothesized that synaptic maturation contributes to neural mechanisms underlying the reduction in behavioral plasticity during song learning in the zebra finch. Most songbirds learn their song during two periods of experience-dependent plasticity lasting several months, after which song becomes highly stereotyped, or "crystallized" (Fig. $1 A$ ). A set of interconnected forebrain nuclei, collectively termed the song system, is involved in song learning and production (Brenowitz et al., 1997; Fig. 1B).

\footnotetext{
Received June 17, 1999; revised Aug. 3, 1999; accepted Aug. 3, 1999.

This work was supported by National Institutes of Health Grants F32 DC00330 to L.L.S. and R01 MH56646 to D.J.P. We thank Jessica Cardin, Long Ding, Michael Farries, Minmin Luo, and Paul Nealen for helpful discussions and comments on an earlier version of this manuscript.

Correspondence should be addressed to David J. Perkel, 215 Stemmler Hall, Department of Neuroscience, University of Pennsylvania, Philadelphia, PA 191046074.

Copyright (C) 1999 Society for Neuroscience $\quad 0270-6474 / 99 / 199107-10 \$ 05.00 / 0$
}

learning but not song production. We examined whether synaptic maturation occurs in either input to RA by recording synaptic currents in brain slices prepared from zebra finches of different ages. We find the motor input from $\mathrm{HVc}$ to RA uses both AMPA receptors (AMPARs) and NMDARs, and synaptic maturation occurs in two phases: an early reduction in duration of NMDAR-mediated synaptic currents in both inputs, and a later reduction in the NMDAR contribution to synaptic responses in the motor pathway. Although NMDAR kinetics change too early to account for crystallization, the reduction of the relative NMDAR contribution to synaptic transmission could contribute to the onset of crystallization. Thus, synaptic maturation events can be temporally distinct and input-specific and may play different roles in behavioral plasticity.

Key words: NMDA receptor; synaptic maturation; developmental plasticity; neural plasticity; songbird; song learning

Nucleus robustus archistriatalis (RA) is a candidate site of plasticity because it is essential for singing and is the principal output of the lateral magnocellular nucleus of the anterior neostriatum (IMAN), which is necessary for song learning but not for singing per se (Bottjer et al., 1984; Sohrabji et al., 1990; Scharff and Nottebohm, 1991). Inputs to RA from the motor nucleus HVc (used here as a proper name) and from IMAN are both glutamatergic but have distinct postsynaptic properties. The EPSP mediated by afferents from HVc is largely blocked by the AMPAR antagonist CNQX, whereas the IMAN input is almost completely blocked by the NMDAR antagonist APV (Kubota and Saito, 1991; Mooney and Konishi, 1991; Mooney, 1992). We used whole-cell voltage-clamp recording of synaptic currents in RA and report here that, in contrast to previous studies, NMDARs contribute substantially to the HVc input at all ages examined. We also confirm previous reports that the IMAN input is mediated predominantly by NMDARs. In addition, we examined synaptic currents in RA at different ages to determine whether and when synaptic maturation occurs in these two inputs. We report two additional findings: (1) the duration of NMDARmediated EPSCs decreases early in development in both inputs to RA; and (2) the relative contribution of NMDARs to synaptic transmission decreases somewhat later in development and occurs only in the motor pathway. These results suggest differential regulation of glutamatergic synaptic maturation and argue against at least one hypothesized mechanism of song crystallization.

Preliminary reports of this work have appeared in abstract form (Perkel, 1994; Stark and Perkel, 1998; Stark and Perkel, 1999).

\section{MATERIALS AND METHODS}

Animals. A protocol approved by the University of Pennsylvania Institutional Animal Care and Use Committee was used in this study. Zebra 

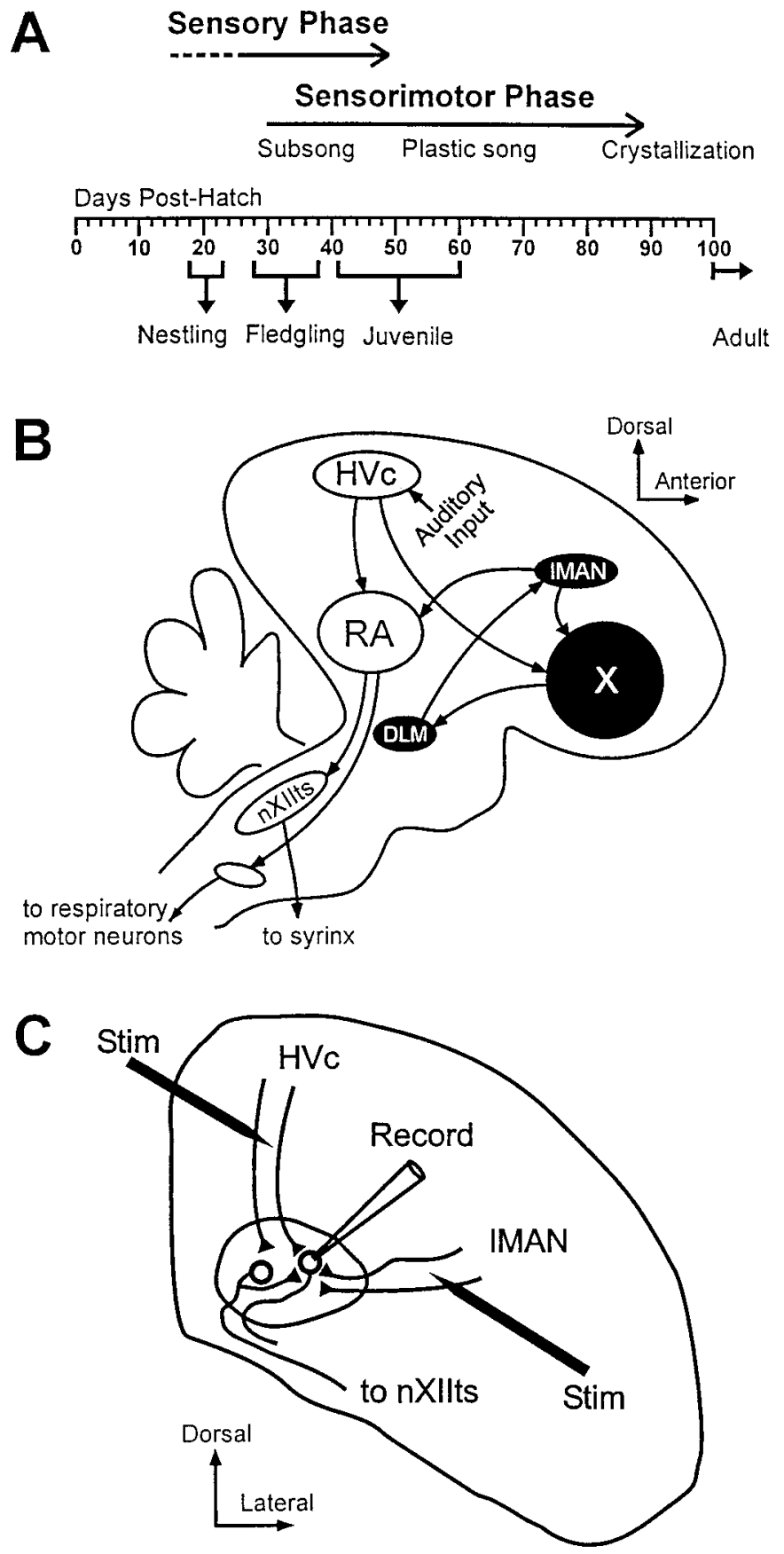

Figure 1. Developmental time line and experimental preparation. $A$, Developmental time line of song learning showing the four age groups of birds examined in relation to the phases of song learning. $B$, Schematic drawing of a sagittal view of the male zebra finch brain, depicting a highly simplified song system. There are two major pathways: the motor pathway ( $H V c, R A$, and $n X I I t s ;$ open nuclei) is necessary for song production; the anterior forebrain pathway (area X,DLM, and $I M A N$; shaded nuclei) is necessary for song learning but not for song production. $C$, Schematic drawing of a coronal slice preparation. We stimulated afferent pathways from $\mathrm{HVc}$ and IMAN and recorded whole-cell synaptic currents from neurons in nucleus RA. These inputs converge on single RA neurons such that EPSCs from each pathway can be recorded in a single postsynaptic neuron. DLM, Medial portion of the dorsolateral nucleus of the anterior thalamus; $H V c$, used here as a proper name; $l M A N$, lateral magnocellular nucleus of the anterior neostriatum; $n X I I t s$, tracheosyringeal portion of the hypoglossal motor nucleus; $R A$, robust nucleus of the archistriatum; $X$, area $\mathrm{X}$ of the parolfactory lobe. finches (Taeniopygia guttata) were obtained either from our own breeding facility (young birds and some adults) or from a local breeder (adult birds only). Birds were housed in cages in two rooms. Each cage contained either a family of birds or a number of adult males. Young male birds were removed to cages with other juveniles $\sim 50 \mathrm{~d}$ after hatching [days post-hatch (DPH)], and thus, were sufficiently exposed to the song of their father during the sensory stage of song learning. The four age groups studied were 18-23 DPH, 28-38 DPH, 41-60 DPH, and $>100$ $\mathrm{DPH}$, corresponding roughly to periods immediately before subsong, at the onset of subsong, at the height of the sensorimotor period, and after song crystallization, respectively (Immelmann, 1969; Arnold, 1975; Fig. $1 A)$. For convenience, these four ages are referred to as nestling, fledgling, juvenile, and adult, respectively. Except where noted, birds were male, and sex was confirmed either by the presence of male secondary sexual characteristics or, in the younger birds, by postmortem visual identification of gonads.

Preparation of slices. Methods for preparing slices have been described elsewhere (Kubota and Saito, 1991; Mooney and Konishi, 1991; Dutar et al., 1998). Briefly, zebra finches were anesthetized by halothane inhalation and killed by decapitation. Coronal slices $(300 \mu \mathrm{m})$ were cut using a vibrating microtome in ice-cold artificial CSF (ACSF; in mM: $\mathrm{NaCl} 119$, $\mathrm{KCl} 2.5, \mathrm{MgSO}_{4} 1.3, \mathrm{NaHPO}_{4} 1, \mathrm{NaHCO}_{3} 26.2$, glucose 11 , and $\mathrm{CaCl}_{2}$ 2.5 ) in which equiosmolar sucrose replaced $\mathrm{NaCl}$ (Aghajanian and Rasmussen, 1989). Slices were placed for $30 \mathrm{~min}$ in a holding chamber containing warm $\left(30^{\circ} \mathrm{C}\right)$ ACSF in which $50 \%$ of the $\mathrm{NaCl}$ had been replaced with sucrose. Slices were then transferred to a second holding chamber containing ACSF with no sucrose. ACSF in both holding chambers was allowed to return to room temperature $\left(22-25^{\circ} \mathrm{C}\right)$. For recording, an individual slice was submerged in a small chamber superfused (1-2 $\mathrm{ml} / \mathrm{min}$ ) with high-divalent cation ACSF (recipe as above, except $4 \mathrm{~mm} \mathrm{CaCl}_{2}, 4 \mathrm{~mm} \mathrm{MgSO}_{4}$, and $100 \mu \mathrm{M}$ picrotoxin). All solutions were bubbled with $95 \% \mathrm{O}_{2}$ and $5 \% \mathrm{CO}_{2}$. All ACSF reagents were purchased from Sigma (St. Louis, MO) or Fisher Scientific (Pittsburgh, PA).

Electrophysiological recording. We recorded from neurons in nucleus RA using the "blind" whole-cell technique (Blanton et al., 1989). Electrode resistance was 4-7 M $\Omega$, and electrodes were filled with whole-cell pipette solution, in mu: Cs gluconate 125, HEPES 10, EGTA 10, $\mathrm{NaCl}$ 8, MgATP 2, and $\mathrm{Na}_{3}$ GTP 0.3, pH 7.3, 290-300 mOsm. Signals were amplified using an Axopatch 1D amplifier (Axon Instruments, Foster City, CA), filtered at $1-3 \mathrm{kHz}$, digitized at twice the filter frequency with a National Instruments (Austin, TX) digitizing board, and acquired using a custom data acquisition program written in LabView (National Instruments) by M. A. Farries and D. J. Perkel. Series resistance $\left(R_{s}\right)$ was monitored throughout each experiment, and traces in different conditions from the same cell were compared only if there was $<20 \%$ difference in $R_{\mathrm{s}}$. Traces shown are an average of 5-20 raw traces.

Using bipolar stainless-steel electrodes (FHC, Bowdoinham, ME), we independently stimulated afferent pathways from $\mathrm{HVc}$ and $\mathrm{MAN}$ to elicit EPSCs in RA neurons with a $10 \mathrm{sec}$ interstimulus interval (Fig. 1C). Membrane potential was initially held at $-80 \mathrm{mV}$, and both afferent pathways were stimulated to identify EPSCs. Membrane potential was then held at $+50 \mathrm{mV}$, where both AMPAR- and NMDAR-mediated components could be studied in the region of linearity of the NMDAR current-voltage relationship (Mayer et al., 1984). EPSCs obtained in ACSF were used only if the synaptic current had a smooth rising phase and a short constant latency (i.e., probably monosynaptic). We recorded from a total of 61 cells in 57 slices from 49 birds, providing monosynaptic inputs from $\mathrm{HVc}$ afferent stimulation in 39 cases and from IMAN afferent stimulation in 35 cases. The drugs, DL-2-amino-5phosphonovaleric acid (APV) and 6-cyano-7-nitroquinoxaline-2,3-dione (CNQX), were purchased from Tocris Cookson (St. Louis, MO) and were bath-applied.

Analysis. We measured the relative contribution of NMDARs to the EPSC in two ways. In the first method, we obtained the NMDA:AMPA $(\mathrm{N}: \mathrm{A})$ ratio by recording a reversed EPSC at $+50 \mathrm{mV}$ before and after application of $10 \mu \mathrm{M}$ CNQX or $50 \mu \mathrm{M}$ APV. The peak current in the presence of the antagonist provided a measure of one component. The other component was measured as the peak of the current resulting from the subtraction of the EPSC recorded in the presence of the antagonist from the control EPSC. CNQX, in addition to blocking the fast AMPAR-mediated current, also partially reduced the slower NMDA current $(31 \pm 4 \%$ reduction, mean $\pm \mathrm{SD}$, data not shown). Before subtraction, the trace recorded in the presence of CNQX was scaled to match the control trace at a point $30 \mathrm{msec}$ after the stimulation artifact, such that the subtraction revealed only the isolated AMPA component. 
The decay time course of the EPSC recorded in the presence of CNQX was unchanged compared with that of the control EPSC, supporting our criteria for minimizing the occurrence of polysynaptic inputs in our data set. In the second method, we obtained a measure of the two components independent of pharmacology. Taking advantage of the different kinetics of the two components, we measured the ratio of the late (NMDA) component to the early (AMPA) component, the Late:Early ratio (Hestrin et al., 1990a; Perkel and Nicoll, 1993). The late component was measured as the mean EPSC amplitude (in picoamperes) in a $20 \mathrm{msec}$ window, starting $30 \mathrm{msec}$ after the stimulus. The early component was measured as the mean amplitude in a $2 \mathrm{msec}$ window during the rising phase, starting at $10 \%$ of peak amplitude. The two methods for estimating the contribution of the NMDAR-mediated component to the total synaptic current were comparable, with the Late:Early ratio reporting a slightly lower estimate of the NMDA contribution (data not shown).

To measure decay kinetics of the NMDAR-mediated synaptic current, we isolated that synaptic component using CNQX, which had no effect on the decay time course (data not shown). Two methods were used to quantify the NMDAR decay kinetics: e-fold decay time and double exponential analysis. e-fold decay was measured as the time (in milliseconds) from peak to peak $\times(1 / \mathrm{e})$. To measure the fast and slow components of the NMDAR-mediated EPSC, we fitted the trace with a double exponential decay function: $\mathrm{Y}(\mathrm{t})=\mathrm{amp} 1 \times \mathrm{e}^{(-\mathrm{K} 1 \times \mathrm{t})}+\mathrm{amp} 2 \times \mathrm{e}^{(-\mathrm{K} 2 \times \mathrm{t})}$ + asymptote, using the iterative CurveFit function (IgorPro 3.12; WaveMetrics, Lake Oswego, OR), which minimized the least-squares difference between the averaged trace and the double exponential function. The asymptote was constrained to the baseline value. We then determined the decay time constants (in milliseconds) of the fast $\left(\tau_{\mathrm{f}}=1 / \mathrm{K} 1\right)$ and slow $\left(\tau_{\mathrm{s}}=1 / \mathrm{K} 2\right)$ components. We also calculated the percent contribution of the slow component to the total NMDAR-mediated current based on the amplitudes of the two components: \% slow $=$ $[a m p 2 /(a m p 1+a m p 2)] \times 100$. EPSC rise times were also calculated as the time (in milliseconds) from 10 to $90 \%$ of peak amplitude.

Unless otherwise specified, one-way ANOVA was used to test for a developmental change in a given measurement. Subsequently, NewmanKeuls tests were used for unplanned pairwise comparisons between groups (Prism 2.01; Graphpad Software, San Diego, CA). Unless otherwise noted, data are presented as mean \pm SD.

\section{RESULTS}

\section{IMAN-RA and HVc-RA synapses use different} complements of glutamate receptor subtype

We recorded reversed synaptic currents from RA neurons at a holding potential of $+50 \mathrm{mV}$ by stimulating the afferent pathways from HVc (HVc-RA EPSCs) and from IMAN (IMAN-RA EPSCs). The NMDAR- and AMPAR-mediated components were studied using CNQX, an antagonist of AMPARs and/or APV, an antagonist of NMDARs. We found that HVc-RA synapses use both NMDARs and AMPARs, whereas IMAN-RA synapses use NMDARs almost exclusively (Fig. 2). Application of $50 \mu \mathrm{M}$ APV blocked the NMDA component of the HVc-RA EPSC, revealing a substantial AMPAR-mediated component with a rapid onset and decay (Fig. $2 A$ ). In contrast, APV blocked nearly all of the IMAN-RA EPSC, revealing only a negligible AMPA component (Fig. 2B). Subsequent addition of $10 \mu \mathrm{M}$ CNQX eliminated the remaining synaptic current (Fig. $2 A, B)$. In separate experiments, antagonists were applied in the reverse order to confirm this effect and to illustrate the shape of the NMDAR-mediated component (Fig. 2C,D). Application of 10 $\mu \mathrm{M}$ CNQX blocked the AMPA component of the HVc-RA EPSC, revealing a substantial NMDA component with a slow time course of onset and decay (Fig. 2C). However, CNQX had minimal effect on the IMAN-RA EPSC (Fig. 2D). Subsequent addition of APV eliminated the remaining synaptic current in both pathways (Fig. 2C,D).

To quantify the contribution of NMDARs to the synaptic current, we calculated the ratio of peak currents mediated by NMDARs and AMPARs (N:A ratio; see Materials and Methods). The median $\mathrm{N}$ :A ratio for $\mathrm{HVc}-\mathrm{RA}$ EPSCs was $>1$ (me-
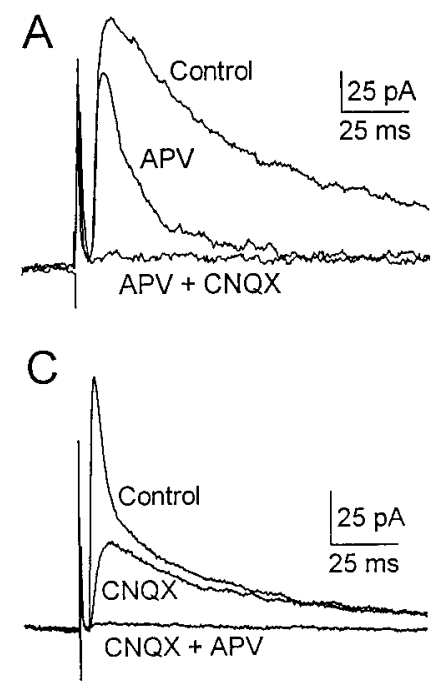

HVc-RA EPSCs
IMAN-RA EPSCs
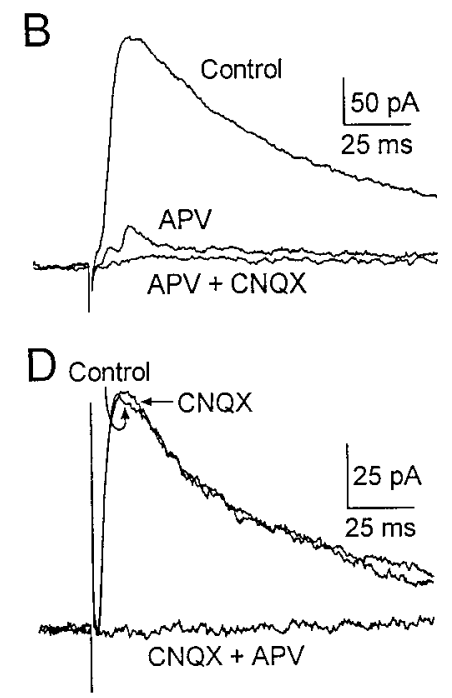

Figure 2. EPSCs from $\mathrm{HVc}$ and IMAN inputs are mediated by different complements of glutamate receptor subtype. EPSCs elicited by $\mathrm{HVc}$ afferent stimulation $(A, C)$ are mediated by both AMPARs and NMDARs, whereas EPSCs elicited by IMAN afferent stimulation $(B, D)$ are mediated almost exclusively by NMDARs. Each panel shows three EPSCs (each an average of 5-20 traces), overlaid and aligned at the time of stimulation. Some stimulus artifacts have been clipped for clarity. APV blocked the NMDA component, revealing a substantial AMPA component in the HVc-RA EPSC $(A)$, and a negligible AMPA component in the IMAN-RA EPSC (B); AMPA components were subsequently blocked by CNQX. Initial application of CNQX blocked the AMPA component in the HVc-RA EPSC, revealing a substantial NMDA component $(C)$, but had minimal effect on the IMAN-RA EPSC $(D)$; NMDA components in both pathways were subsequently blocked by APV. EPSCs in $A$ and $B$ are from a single neuron from a $43 \mathrm{DPH}$ bird; EPSCs in $C$ are from an adult bird; EPSCs in $D$ are from a $42 \mathrm{DPH}$ bird.

dian, 1.44; range, 0.57-3.88; $n=19$ ), indicating a substantial NMDAR contribution in the HVc input. N:A ratios for IMAN-RA EPSCs were much larger (median, 10.27), and the AMPA component was often indistinguishable from background, resulting in an apparently non-normal distribution of $\mathrm{N}$ :A ratios with a large range $(2.61-98.27 ; n=23)$. Figure 3 shows that $\mathrm{HVc}$ and $1 \mathrm{MAN} \mathrm{N}$ :A ratios, combining all age groups, are significantly different (Mann-Whitney $U$ test; $U=7.00 ; p<0.0001$ ). These results confirm previous reports that $1 \mathrm{MAN}-\mathrm{RA}$ synapses are mediated almost exclusively by NMDARs (Kubota and Saito, 1991; Mooney and Konishi, 1991; Mooney, 1992). However, several IMAN-RA synapses exhibited a measurable AMPA component, suggesting a minor contribution of AMPARs in this pathway. In summary, in contrast to previous results, we show that the HVc-RA connection is a dual-component synapse, mediated not only by AMPARs, but also by a substantial contribution from NMDARs.

\section{The contribution of NMDARs to HVc-RA EPSCs decreases during development}

The contribution of the NMDAR to the dual-component EPSC decreases during development in many systems (Fox et al., 1989; Crair and Malenka, 1995; Wu et al., 1996). We examined the N:A ratio for $\mathrm{HVc}-\mathrm{RA}$ EPSCs in three age groups: fledgling, juvenile, and adult (Fig. $4 A_{1}, A_{2}$ ). There was an overall developmental decrease in $\mathrm{N}$ :A ratio, however the post hoc tests were unable to 


\section{$\mathrm{N}$ :A ratio for all ages combined} Median (IQR)

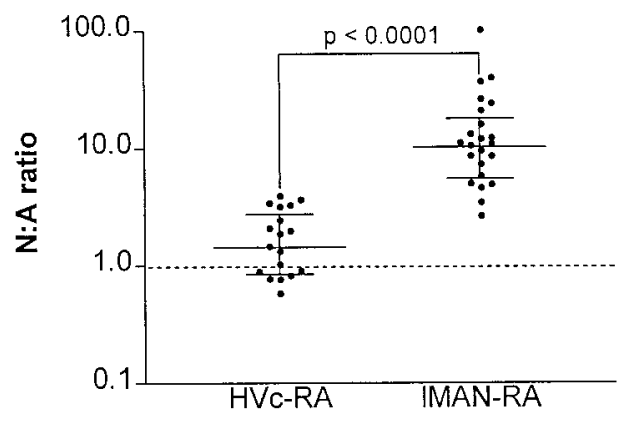

Figure 3. Comparison of NMDA:AMPA ratio between HVc-RA and IMAN-RA EPSCs. N:A ratio values (and median plus interquartile range) for all ages examined, plotted on a log scale. The dotted line indicates a 1:1 ratio. In this and subsequent figures, each individual symbol represents data from one cell. Median N:A ratio for IMAN-RA EPSCs is approximately tenfold higher than that for HVc-RA EPSCs, illustrating that IMAN-RA EPSCs are mediated predominantly by NMDARs, whereas HVc-RA EPSCs are mediated by both NMDARs and AMPARs.
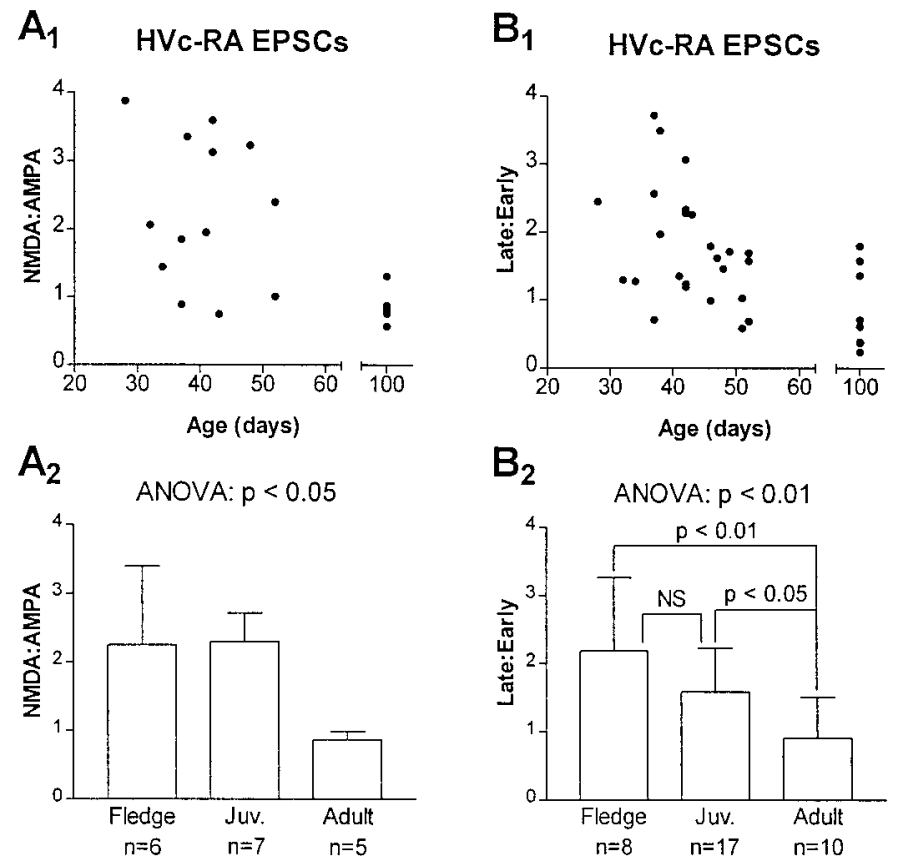

Figure 4. Developmental reduction in NMDAR contribution to total synaptic current. $A_{1}$, Scatterplot of NMDA:AMPA ratio versus age for $\mathrm{HVc}-\mathrm{RA}$ EPSCs. In this and subsequent figures, cells from adult birds are plotted at $100 \mathrm{DPH} . \mathrm{A}_{2}$, Mean N:A ratio values $( \pm \mathrm{SD})$ for $\mathrm{HVc}-\mathrm{RA}$ EPSCs. The N:A ratio decreased during development, but post hoc tests did not identify differences between groups. $B_{1}$, Scatterplot of Late:Early ratio, an independent measure of the contribution of NMDAR to the total EPSC, versus age. $B_{2}$, Mean Late:Early ratio values $( \pm S D)$ for HVc-RA EPSCs. Late:Early ratio also decreased during development. Post hoc tests revealed that the decrease in Late:Early ratio occurred between the juvenile and adult stages, but inspection of the scatterplot $\left(B_{1}\right)$ suggests that the decrease may occur during the juvenile stage. See Table 1 for statistics. NS, Not significant.

elucidate when the change occurred (Table $1 A$ ). We performed an independent measurement of the relative contributions of NMDA and AMPA components, the Late:Early ratio, based not on pharmacological manipulations but on the different time course of these two components (Fig. $4 B_{1}$, see Materials and Methods). Several additional cells, to which neither CNQX nor APV was applied, contributed to this analysis. As with the N:A ratio, there was an overall developmental decrease in the Late: Early ratio (Table $1 A$; Fig. $4 B_{2}$ ). Post hoc comparisons showed that the bulk of this change occurred between the juvenile and adult stages; however, inspection of the Late:Early ratio plotted against age suggests that the decrease may occur within the juvenile period (Fig. $4 B_{1}$ ). Thus, it appears that the contribution of NMDARs to the HVc-RA synaptic connection decreases relatively late in development, certainly after 45 DPH. In addition, the contribution of NMDARs to synaptic transmission in the HVc pathway decreases approximately twofold by adulthood.

$\mathrm{N}$ :A ratio and Late:Early ratios from nestlings are not included in Figure 4 or in statistical analyses for two reasons. First, the frequency of obtaining an acceptable HVc-RA EPSC in nestlings was very low (3 of 42 attempts; seven other inputs were polysynaptic and were not used), and only one of these yielded $\mathrm{N}$ :A data (N:A, 0.73). In all cells, HVc afferents were stimulated while holding membrane potential at $-80 \mathrm{mV}$ and at $+50 \mathrm{mV}$ to test for the possibility of $\mathrm{HVc}$ inputs mediated exclusively by NMDARs. No such "silent" synapses (Isaac et al., 1995; Liao et al., 1995) were found in this pathway. Thus, consistent with other reports (Mooney, 1992; Akutagawa and Konishi, 1994; Mooney and Rao, 1994; Vicario et al., 1994), we find that the HVc input to RA is very sparse at the nestling stage. Second, it was not possible to measure the Late:Early ratio for nestlings because of a confounding effect, i.e., the decay kinetics of EPSCs in the youngest birds are significantly longer than in the other three age groups (see below). The small sample size from the nestling stage does not affect our conclusion that the contribution of NMDARs decreases quite late in juvenile development.

\section{Decay kinetics of IMAN-RA and HVc-RA EPSCs decrease early in song development}

In addition to developmental changes in N:A ratio, the decay kinetics of NMDAR-mediated synaptic currents change during development (Carmignoto and Vicini, 1992; Hestrin, 1992; Crair and Malenka, 1995; Wu et al., 1996; Livingston and Mooney, 1997; Shi et al., 1997; White et al., 1999). In the present study, NMDAR-mediated currents (in the presence of CNQX) had longer duration in nestlings than in all three older age groups (Fig. 5). The rare recordings of $\mathrm{HVc}-\mathrm{RA}$ EPSCs in nestlings $(n=2)$ revealed a time course of maturation similar to that for IMAN-RA EPSCs.

To quantify the decay time course of NMDAR-mediated currents, we measured e-fold decay time and fitted currents with a double exponential decay function. Both IMAN-RA and HVc-RA EPSCs exhibited a significant developmental reduction in e-fold decay time (Table 1, Fig. $6 A_{1}, B_{1}$ ). Post hoc tests showed that e-fold decay time for the nestling group was significantly different from that for each of the other three groups, but that fledglings, juveniles, and adults were not significantly different from one another (Table 1, Fig. $6 A_{2}, B_{2}$ ). Thus e-fold decay time decreased significantly between the nestling and fledgling groups and then remained at the same level throughout the remainder of development.

NMDAR-mediated synaptic currents in other systems are composed of both a fast and a slow component, for which the decay time constants are determined by the subunit composition of the receptor (Hestrin et al., 1990b; Lester et al., 1990; Williams et al., 1993; Monyer et al., 1994; Flint et al., 1997). 
Table 1. Statistical analysis of synaptic maturation of HVc and IMAN inputs to RA

\begin{tabular}{|c|c|c|c|c|c|c|c|c|c|c|c|}
\hline \multirow[b]{2}{*}{ Parameter } & \multicolumn{4}{|c|}{ Mean \pm SD } & \multirow[b]{2}{*}{ One-way ANOVA } & \multicolumn{6}{|c|}{ Newman-Keuls tests ( $p$ values) } \\
\hline & Nest. & Fledge & Juv. & Adult & & $\mathrm{N}$ vs $\mathrm{F}$ & $\mathrm{N}$ vs $\mathrm{J}$ & $\mathrm{N}$ vs $\mathrm{A}$ & F vs $J$ & F vs A & $\mathrm{J}$ vs A \\
\hline A. HVc-RA EPSCs & $n=2^{a}$ & $n=7^{a}$ & $n=8^{a}$ & $n=6^{a}$ & & & & & & & \\
\hline NMDA:AMPA & $0.73^{b}$ & $2.2 \pm 1.1^{c}$ & $2.3 \pm 1.1^{d}$ & $0.87 \pm 0.27^{e}$ & $F_{(2,15)}=3.75 ; p<0.05$ & - & - & - & NS & NS & NS \\
\hline Late:Early & - & $2.2 \pm 1.1^{f}$ & $1.6 \pm .64^{g}$ & $0.90 \pm 0.61^{h}$ & $F_{(2,32)}=6.61 ; p<0.005$ & - & - & - & NS & $<0.01$ & $<0.05$ \\
\hline e-fold decay (msec) & $270 \pm 16$ & $66 \pm 30$ & $59 \pm 17$ & $64 \pm 24$ & $F_{(3,19)}=50.69 ; p<0.0001$ & $<0.001$ & $<0.001$ & $<0.001$ & NS & NS & NS \\
\hline Decay $\tau_{\mathrm{f}}(\mathrm{msec})$ & $120 \pm 100$ & $29 \pm 32$ & $31 \pm 21$ & $20 \pm 7.8$ & $F_{(3,19)}=5.30 ; p<0.01$ & $<0.01$ & $<0.01$ & $<0.01$ & NS & NS & NS \\
\hline Decay $\tau_{\mathrm{s}}(\mathrm{msec})$ & $360 \pm 47$ & $110 \pm 49$ & $110 \pm 59$ & $100 \pm 56$ & $F_{(3,19)}=13.00 ; p<0.0001$ & $<0.001$ & $<0.001$ & $<0.001$ & NS & NS & NS \\
\hline$\%$ slow & $49 \pm 27$ & $69 \pm 20$ & $60 \pm 24$ & $68 \pm 11$ & $F_{(3,19)}=0.68 ; \mathrm{NS}$ & - & - & - & - & - & - \\
\hline Rise time (msec) & $13 \pm 1.1$ & $7.0 \pm 2.9$ & $7.8 \pm 2.5$ & $5.7 \pm 1.5$ & $F_{(3,19)}=4.97 ; p<0.02$ & $<0.05$ & $<0.05$ & $<0.01$ & NS & NS & NS \\
\hline B. IMAN-RA EPSCs & $n=10$ & $n=9$ & $n=12$ & $n=4$ & & & & & & & \\
\hline e-fold decay (msec) & $220 \pm 63$ & $94 \pm 31$ & $72 \pm 20$ & $77 \pm 23$ & $F_{(3,31)}=30.04 ; p<0.0001$ & $<0.001$ & $<0.001$ & $<0.001$ & NS & NS & NS \\
\hline Decay $\tau_{\mathrm{f}}(\mathrm{msec})$ & $52 \pm 23$ & $35 \pm 15$ & $26 \pm 17$ & $30 \pm 8.6$ & $F_{(3,31)}=4.20 ; p<0.02$ & NS & $<0.01$ & NS & NS & NS & NS \\
\hline Decay $\tau_{\mathrm{s}}(\mathrm{msec})$ & $300 \pm 76$ & $180 \pm 47$ & $120 \pm 47$ & $140 \pm 55$ & $F_{(3,31)}=19.00 ; p<0.0001$ & $<0.001$ & $<0.001$ & $<0.001$ & $<0.05$ & NS & NS \\
\hline$\%$ slow & $74 \pm 9.0$ & $54 \pm 22$ & $70 \pm 13$ & $59 \pm 4.9$ & $F_{(3,31)}=3.70 ; p<0.03$ & $<0.05$ & NS & NS & NS & NS & NS \\
\hline Rise time (msec) & $8.5 \pm 2.9$ & $6.1 \pm 2.5$ & $6.5 \pm 1.9$ & $5.6 \pm 0.6$ & $F_{(3,31)}=2.52 ; \mathrm{NS}$ & - & - & - & - & - & - \\
\hline
\end{tabular}

${ }^{a}$ Except where noted.

${ }^{b} n=1$.

${ }^{c} n=6$.

${ }^{d} n=7$.

${ }^{e} n=5$.

$f_{n}=8$.

$g_{n}=17$.

${ }^{h_{n}}=10$.

$\mathrm{N}$, nestling; F, fledgling; J, juvenile; A, adult; NS, not significant.

A Normalized IMAN-RA EPSCs B Normalized HVc-RA EPSCs
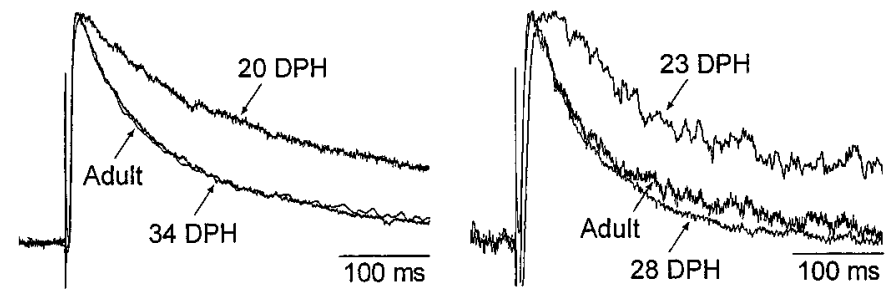

Figure 5. Example traces showing a developmental decrease in duration of NMDAR-mediated EPSCs. Normalized EPSCs from different ages for both IMAN $(A)$ and $\mathrm{HVc}(B)$ inputs to RA. The duration of the isolated NMDAR-mediated current decreased dramatically between the nestling stage (20 DPH in $A, 23 \mathrm{DPH}$ in $B$ ) and the fledgling stage (34 DPH in $A$, $28 \mathrm{DPH}$ in $B$ ). There was no further change between fledglings and adults. Juvenile examples are omitted for clarity, but the time course resembles that of the fledgling and adult traces.

There are three variables that could change to affect the duration of the synaptic current: the fast decay time constant $\left(\tau_{\mathrm{f}}\right)$, the slow decay time constant $\left(\tau_{\mathrm{s}}\right)$, and the percentage contribution of the slow component (\% slow) to the total NMDAR-mediated current (see Materials and Methods). In several other systems, the \% slow decreases during development (Carmignoto and Vicini, 1992; Hestrin, 1992; Livingston and Mooney, 1997).

We performed a double exponential analysis on IMAN-RA and $\mathrm{HVc}-\mathrm{RA}$ EPSCs to test the hypothesis that a decrease in $\%$ slow was the critical factor in decreasing the duration of the synaptic currents. Unexpectedly, the most dramatic effect was a decrease in $\tau_{\mathrm{s}}$ for both $1 \mathrm{MAN}-\mathrm{RA}$ and $\mathrm{HVc}-\mathrm{RA}$ EPSCs (Fig. 7). Similar to the e-fold decay time course, the critical drop in $\tau_{\mathrm{s}}$ occurred between the nestling and fledgling age groups, with no further developmental change (Fig. 7, Table $1)$. The fast time constant $\left(\tau_{\mathrm{f}}\right)$ decreased during development for both input pathways, and \% slow also decreased, but only in the 1 MAN pathway (Fig. 7, Table 1). The results of the post hoc tests for $\tau_{\mathrm{f}}$ and $\%$ slow are difficult to interpret with confidence, and the effects were quite small. Although small changes in $\tau_{\mathrm{f}}$ and \% slow might have some effect on the duration of the NMDAR-mediated EPSC, the large drop in duration between the nestling and fledgling stages appears to be mediated primarily by a decrease in $\tau_{\mathrm{s}}$.

Overall, for both e-fold decay and double exponential analyses, we found that the decay kinetics for both IMAN and HVc inputs to RA decreased between the nestling and fledgling age groups, and that there was no difference in any of the measures among the three older groups. One possible confounding effect was that birds in the nestling age group do not exhibit secondary sexual characteristics. For the HVc-RA EPSCs, both data points in the nestling group were from confirmed male birds. However, not all birds contributing to the nestling $1 \mathrm{MAN}$ data were male; four birds were male, four birds were female, and two birds were of unconfirmed sex. $t$ tests comparing confirmed males versus females plus birds of unknown sex indicated that there was no difference between these two groups $(p>0.05$ in all cases, data not shown), so all data were pooled, and we did not consider the sex difference to confound the data.

Finally, inspection of the overlaid traces in Figure 5 suggests that the rise time of NMDAR-mediated EPSCs might also change with development. One-way ANOVAs showed that there was no developmental change in rise time of IMAN-RA EPSCs, but there was a change for HVc-RA EPSCs (Table 1). As for previous analyses of kinetic properties, subsequent post hoc analyses of the rise times for HVc-RA EPSCs indicated that the 

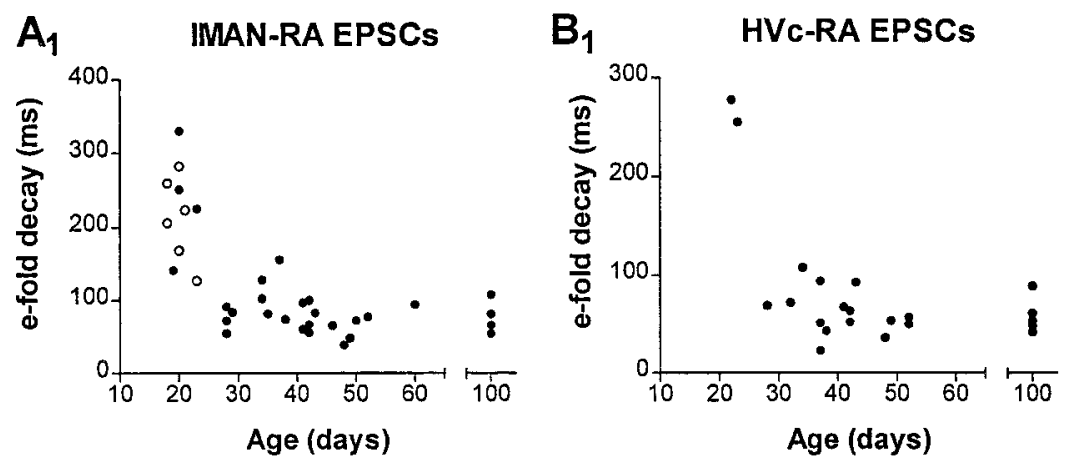

Figure 6. e-fold decay time decreases early in song development. $A_{1}$, Scatterplot of e-fold decay times versus age for IMAN-RA EPSCs. For this and subsequent figures, filled symbols are from males, open symbols are from females or birds of unknown sex (see Materials and Methods). $A_{2}$, Mean e-fold decay time ( $\pm \mathrm{SD})$ for IMAN-RA EPSCs. $B_{1}$, Scatter plot of e-fold decay times versus age for $\mathrm{HVc}-\mathrm{RA}$ EPSCs. $B_{2}$, Mean e-fold decay time $( \pm$ SD) for HVc-RA EPSCs. For both inputs, nestlings had significantly longer e-fold decay times than any of the other age groups $\left({ }^{* * *} p<\right.$ 0.001 , comparing nestlings with each of the other groups). There were no significant differences among fledglings, juveniles, and adults, indicating that e-fold decay time stabilized by the fledgling stage. See Table 1 for statistics.
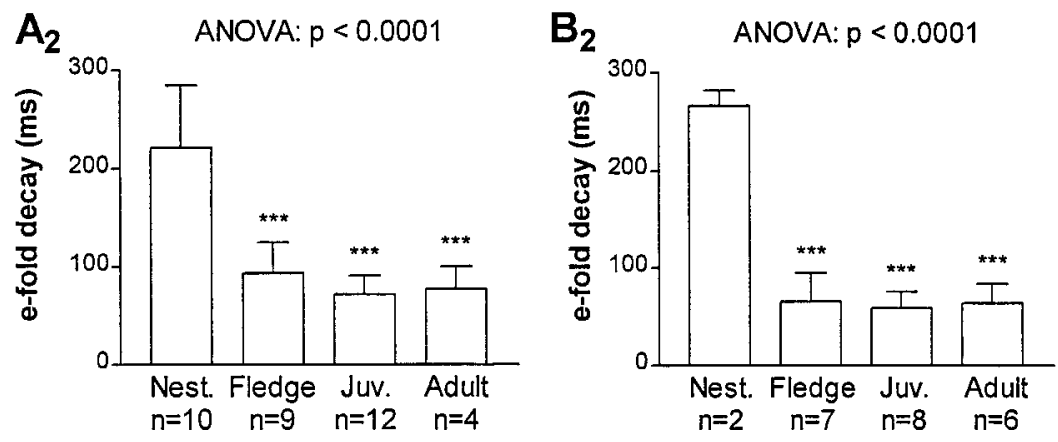

difference lies between the nestling and fledgling stages and that there is no difference among the three older age groups.

\section{DISCUSSION}

Here we confirm previous findings that the lMAN input to RA is mediated almost exclusively by NMDARs (Kubota and Saito, 1991; Mooney and Konishi, 1991; Mooney, 1992). In contrast with those reports, we find that the HVc input uses both AMPARs and NMDARs at all ages examined. As in other developmentally plastic systems, we observe two forms of synaptic maturation in the inputs to RA (Fig. $8 A-C$ ). Reductions in duration of NMDAR-mediated EPSCs occur in both pathways at $\sim 25 \mathrm{DPH}$. Somewhat later in development, the HVc input undergoes a reduction in the relative contribution of NMDARs to synaptic transmission. These results suggest separate regulation of these two forms of synaptic maturation and constrain their respective roles in modulating song learning.

\section{Differential synaptic maturation of two converging inputs}

Studies in mammals and amphibians have identified two major functional changes in glutamatergic synaptic transmission that occur hand in hand: a decrease in the N:A ratio and a shortening of NMDAR-mediated EPSCs (Crair and Malenka, 1995; Wu et al., 1996). Because of their spatial and temporal coincidence, the two components have been lumped under the heading synaptic maturation. We find that changes in NMDAR kinetics in both input pathways to RA are complete by $\sim 25 \mathrm{DPH}$, whereas changes in the NMDAR contribution to synaptic transmission from the $\mathrm{HVc}$ input occur at least 3 weeks later. The synaptic connections between $\mathrm{HVc}$ and RA were rare before $30 \mathrm{DPH}$. Nevertheless, the few HVc-RA EPSCs we recorded at this early age had slow decay kinetics, suggesting that the initial HVc axons innervating RA encounter slow NMDARs, but that quickly the kinetics accelerate. Because we rarely observed a measurable AMPA component in the IMAN input, it appears that this pathway undergoes only the kinetic element of synaptic maturation.

Our results are summarized in Figure $8 D$, illustrating the spatial and temporal dissociation of the two forms of synaptic maturation. That these two processes occur in the same population of postsynaptic neurons suggests that they are subject to differential control. The innervation of RA by HVc inputs and the ensuing arrival of motor signals, may trigger the change in NMDAR kinetics in the postsynaptic cells. Alternatively, some other signal could trigger both the changes in kinetics and the massive innervation of RA by $\mathrm{HVc}$ axons. The change in relative contribution of NMDARs to synaptic transmission occurs at least 3 weeks later, well after $\mathrm{HVc}$ has fully innervated RA (Akutagawa and Konishi, 1994; Mooney and Rao, 1994). It remains to be seen how a single postsynaptic neuron can coordinate different phases of synaptic maturation at different populations of synapses.

\section{Differential glutamate receptor complements mediating inputs to RA neurons}

Three previous studies using sharp electrode intracellular recording under current-clamp conditions reported that the input from IMAN to RA was almost entirely blocked by APV and was only slightly reduced by CNQX (Kubota and Saito, 1991; Mooney and Konishi, 1991; Mooney, 1992). Conversely, they found that the HVc input was nearly blocked by CNQX and was only slightly reduced by APV. We confirm that the IMAN input is almost exclusively mediated by NMDARs in adults and extend that result to birds as young as $18 \mathrm{DPH}$. In contrast, our whole-cell voltage-clamp recordings revealed that, from the time HVc axons first innervate RA through adulthood, a substantial NMDAR-mediated component contributes to synaptic transmission in this pathway. Earlier experiments may not have revealed a substantial NMDA component in the HVc pathway because, under current-clamp conditions near resting potential, stimulus intensities necessary to activate NMDARs 


\section{A IMAN-RA EPSCs}
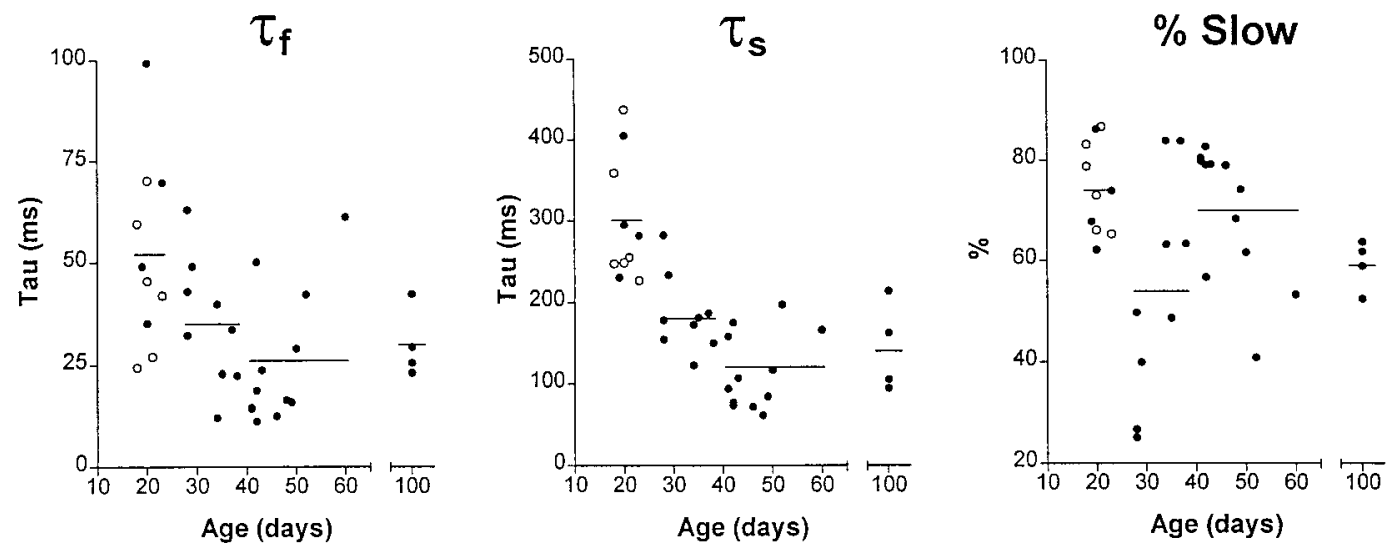

B HVc-RA EPSCs
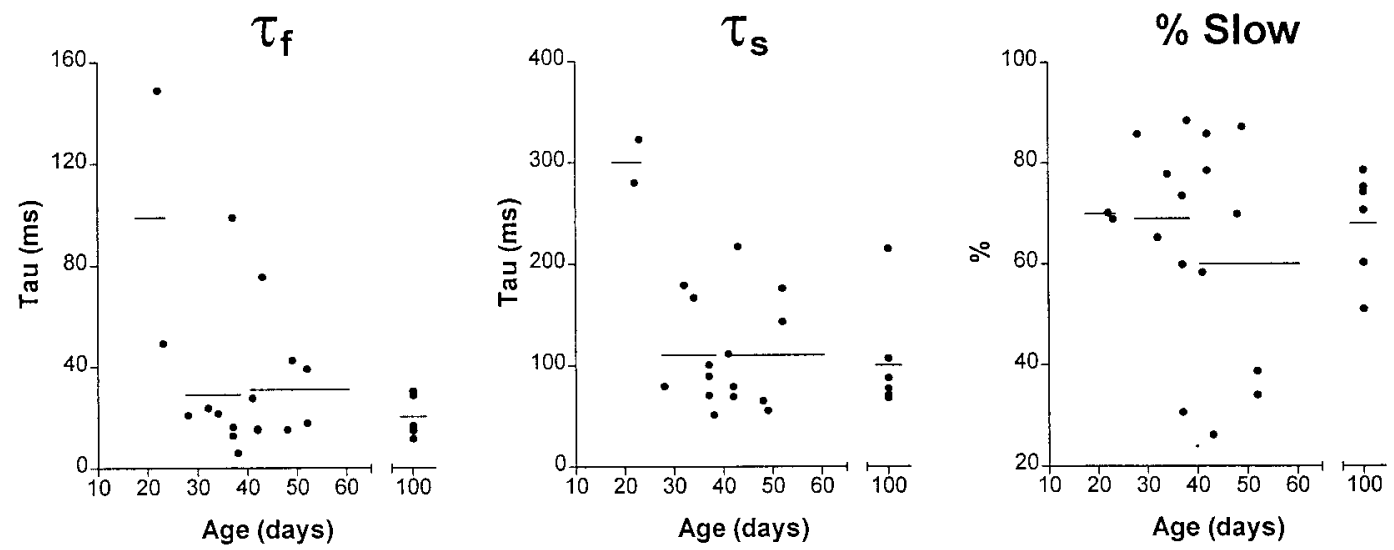

Figure 7. Decay time constants decrease early in song development. Scatterplots of three variables $\left(\tau_{\mathrm{f}}, \tau_{\mathrm{s}}, \%\right.$ slow $)$ from the double-exponential fits of IMAN EPSCs $(A)$ and HVc EPSCs $(B)$ versus age. Horizontal lines indicate the mean for each value within an age group. Except for adults, the length of each line indicates the age range of each group used for ANOVA analysis. Groups are as in Figure 6 . For both input pathways, both the fast $\left(\tau_{\mathrm{f}}\right)$ and slow $\left(\tau_{\mathrm{s}}\right)$ decay time constants of NMDAR-mediated EPSCs decreased with development. The most influential effect on the overall time course of EPSCs was the decrease in $\tau_{\mathrm{s}}$ between the nestling and fledgling stages. The relative amplitude of the slow component (\% slow) showed a small but significant decrease between the nestling and fledgling stages in the lMAN pathway, but did not change during development in the HVc pathway. See Table 1 for statistics.

would have elicited action potentials. Perhaps in the currentclamp studies it was possible to increase stimulation intensity in the IMAN pathway enough to elicit NMDAR-mediated EPSPs because there are few, if any, functional AMPARs at IMAN-RA synapses.

In addition to their important role in triggering neural plasticity, NMDARs also contribute to basic synaptic transmission (Salt, 1986; Fox et al., 1989; Schoppa et al., 1998). For example, NMDARs transmit visual responses in developing and adult visual cortex (Tsumoto et al., 1987; Fox et al., 1989; Scharfman et al., 1990; Kwon et al., 1991) and can contribute to generation of motor behavior (Sigvardt et al., 1985; Wallén and Grillner, 1987). Our observation of a strong NMDA component in the motor input to RA is consistent with a role for NMDARs in song production. Indeed, infusion of APV into RA has been reported to block song production (Lombardino and Nottebohm, 1993). Blockade of the NMDAR-mediated IMAN input cannot explain this result, because $1 \mathrm{MAN}$ lesions in adults do not alter song production (Bottjer et al., 1984; Sohrabji et al., 1990; Scharff and Nottebohm, 1991) and because lidocaine injection into IMAN does not preclude the APV effect in RA (Lombardino and Nottebohm, 1993). Thus, each form of synaptic maturation in RA could alter both synaptic transmission and plasticity.

RA projection neurons make collateral excitatory synapses onto their neighbors, which, like HVc-RA synapses, are mediated by both AMPARs and NMDARs (Perkel, 1995). Thus, these collateral synapses may play an important role in mediating song learning and production. Additionally, they may provide depolarization needed to activate IMAN-RA NMDARs, especially in nestlings before $\mathrm{HVc}$ innervation of RA. It will be important to determine whether and when synaptic maturation occurs in the RA-RA collateral synapses.

\section{Possible mechanisms of the two stages of synaptic maturation}

The duration of mammalian NMDAR-mediated EPSCs is governed by the glutamate affinity of the receptor (Lester et al., 1990; Lester and Jahr, 1992). In other systems, NMDAR-mediated EPSCs show fast and slow decay phases (Carmignoto and Vicini, 

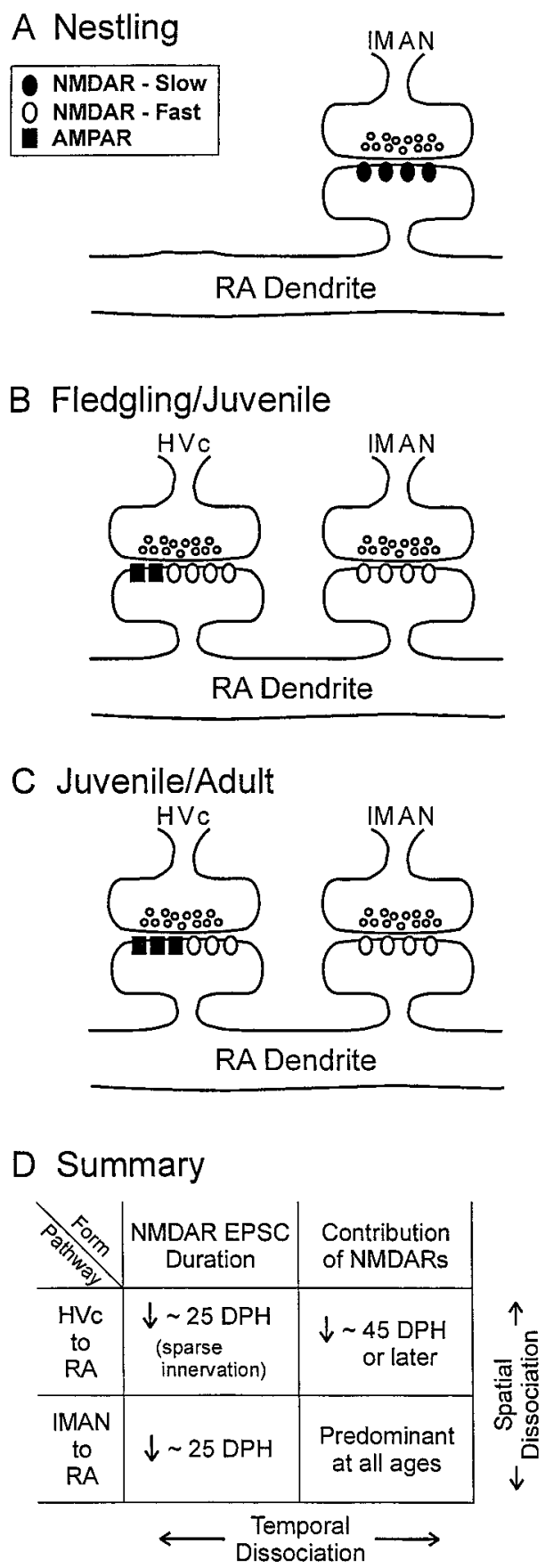

Figure 8. Schematic representation of two-stage, input-specific synaptic maturation in RA neurons. $A$, In nestlings, NMDARs with slow decay kinetics (filled ovals) mediate synaptic transmission at IMAN-RA synapses. At this age, HVc inputs are rare and are not shown here; however, the few NMDAR-mediated currents we have recorded had slow decay times. $B$, At the fledgling and juvenile stages, NMDARs mediating both HVc-RA and IMAN-RA EPSCs have fast decay kinetics (open ovals). $\mathrm{HVc}$ inputs are mediated by both NMDARs and AMPARs (filled rectangles) with an $\sim 2: 1$ ratio. $C$, By adulthood, the relative contributions of NMDARs and AMPARs have decreased to an $\sim 1: 1$ ratio, and the decay kinetics of NMDARs remain fast in both input pathways. The symbol key, inset in $A$, applies to $A-C$. $D$, Summary of our observations, depicting the spatial and temporal dissociation of two forms of synaptic maturation in nucleus RA.
1992; Hestrin, 1992; Wu et al., 1996), possibly reflecting colocalization of two forms of NMDAR, each with a different affinity for glutamate and/or glycine (Zhong et al., 1996; Kew et al., 1998). In these systems, synaptic maturation of the NMDAR current's decay time course involves a relative reduction in the contribution of the slow component to the synaptic current (\% slow), with little change in the time constants of the two individual phases. A developmental change in the abundance of fast and slow isoforms is thought to be mediated by a change in the degree of expression of different NR2 subunits (Williams et al., 1993; Sheng et al., 1994; Zhong et al., 1996; Flint et al., 1997; Kew et al., 1998).

In thalamic inputs from the medial portion of the dorsolateral nucleus of the anterior thalamus (DLM) to zebra finch IMAN, the duration of NMDAR-mediated EPSCs decreases between $\sim 30$ and 40 DPH (Livingston and Mooney, 1997; White et al., 1999), slightly later than the decrease we observed at IMAN-RA synapses. Whereas similar changes occur in IMAN and RA, the underlying mechanisms of this decrease appear to be different within the two nuclei. In DLM-lMAN synapses, the fast and slow decay time constants did not change, but the relative proportion of these components was the critical factor accelerating the kinetics (Livingston and Mooney, 1997). In RA, we observed developmental changes in the time constants themselves, with little or no change in their relative contributions. White et al. (1999) also described a developmental reduction in EPSC decay time course in the IMAN-RA pathway, a process similar in onset but more protracted than we observed.

Boettiger and Doupe (1998) reported a greater effect of APV on 1MAN-IMAN synapses than on DLM-lMAN synapses in 18-25 DPH zebra finches, presumably mediated by different N:A ratios at these connections. White et al. (1999) found that androgen treatment from 15 to $25 \mathrm{DPH}$ reduced a different measure of the NMDAR contribution to synaptic transmission in thalamic inputs to IMAN. It will be interesting to determine whether N:A ratio at synapses in $1 \mathrm{MAN}$ changes developmentally, and, if so, whether the change coincides with the change in kinetics (Livingston and Mooney, 1997; White et al., 1999).

The molecular processes underlying maturation of NMDAR decay kinetics at DLM-1MAN and IMAN-RA synapses are likely different. Developmental changes in binding of the broadspectrum NMDAR antagonist MK-801 and the subunit-specific ligand ifenprodil suggest there is developmental regulation of NMDAR density and subunit expression within IMAN (Aamodt et al., 1994; Basham et al., 1997; Basham et al., 1999). The possibility of a developmental change in NR2 subunit expression within RA has not been tested. The mechanism underlying the observed change in NMDAR-mediated EPSC duration in RA can be explained by either (1) the replacement of two "immature" isoforms with two "mature" isoforms, maintaining their relative proportions, or (2) wholesale replacement of a single immature NMDAR holomer, having complex biophysical properties giving rise to fast and slow decay phases, with a mature holomer having faster decay time constants.

\section{Implications for song learning}

We have begun to address possible neural mechanisms of song learning by examining developmental regulation of NMDARmediated synaptic transmission in nucleus RA of the zebra finch, in relation to different phases of song learning. We originally predicted that in RA, synaptic maturation (both forms) would occur concomitantly with song crystallization. 
We found that only one form of synaptic maturation occurs during the sensorimotor learning phase. Whether this represents the unfolding of a developmental program or contributes in some way to changes in song learning ability remains unknown. Nonetheless, during the sensorimotor phase and into adulthood, NMDAR kinetic properties do not change. Our observations thus argue against shortening of NMDAR time course in RA as a mechanism for crystallization.

\section{REFERENCES}

Aamodt SM, Nordeen EJ, Nordeen KW (1994) Early isolation from conspecific song does not affect the normal developmental decline of $\mathrm{N}$-methyl-D-aspartate receptor binding in an avian song nucleus. J Neurobiol 27:76-84.

Aghajanian GK, Rasmussen K (1989) Intracellular studies in the facial nucleus illustrating a simple new method for obtaining viable motoneurons in adult rat brain slices. Synapse 3:331-338.

Akutagawa E, Konishi M (1994) Two separate areas of the brain differentially guide the development of a song control nucleus in the zebra finch. Proc Natl Acad Sci USA 91:12413-12417.

Arnold AP (1975) The effects of castration on song development in zebra finches (Poephila guttata). J Exp Zool 191:261-278.

Basham ME, Nordeen EJ, Nordeen KW (1997) Developmental regulation of NMDA2B receptor binding in the zebra finch anterior forebrain. Soc Neurosci Abstr 23:797.

Basham ME, Sohrabji F, Singh TD, Nordeen EJ, Nordeen KW (1999) Developmental regulation of NMDA receptor $2 \mathrm{~B}$ subunit mRNA and ifenprodil binding in the zebra finch anterior forebrain. J Neurobiol 39:155-167.

Blanton MG, Lo Turco JJ, Kriegstein AR (1989) Whole cell recording from neurons in slices of reptilian and mammalian cerebral cortex. J Neurosci Methods 30:203-210.

Boettiger CA, Doupe AJ (1998) Intrinsic and thalamic excitatory inputs onto songbird LMAN neurons differ in their pharmacological and temporal properties. J Neurophysiol 79:2615-2628.

Bottjer SW, Miesner EA, Arnold AP (1984) Forebrain lesions disrupt development but not maintenance of song in passerine birds. Science 224:901-903.

Brenowitz EA, Margoliash D, Nordeen KW (1997) An introduction to birdsong and the avian song system. J Neurobiol 33:495-500.

Carmignoto G, Vicini S (1992) Activity-dependent decrease in NMDA receptor responses during development of the visual cortex. Science 258:1007-1011.

Constantine-Paton M, Cline HT, Debski EA (1990) Patterned activity, synaptic convergence, and the NMDA receptor in developing visual pathways. Annu Rev Neurosci 13:129-154.

Crair MC, Malenka RC (1995) A critical period for long-term potentiation at thalamocortical synapses. Nature 375:325-328.

Dutar P, Vu HM, Perkel DJ (1998) Multiple cell types distinguished by physiological, pharmacological, and anatomic properties in nucleus $\mathrm{HVc}$ of the adult zebra finch. J Neurophysiol 80:1828-1838.

Flint AC, Maisch US, Weishaupt JH, Kriegstein AR, Monyer H (1997) NR2A subunit expression shortens NMDA receptor synaptic currents in developing neocortex. J Neurosci 17:2469-2476.

Fox K, Zahs K (1994) Critical period control in sensory cortex. Curr Opin Neurobiol 4:112-119.

Fox K, Sato H, Daw N (1989) The location and function of NMDA receptors in cat and kitten visual cortex. J Neurosci 9:2443-2454.

Hestrin S (1992) Developmental regulation of NMDA receptormediated synaptic currents at a central synapse. Nature 357:686-689.

Hestrin S, Nicoll RA, Perkel DJ, Sah P (1990a) Analysis of excitatory synaptic action in pyramidal cells using whole-cell recording from rat hippocampal slices. J Physiol (Lond) 422:203-225.

Hestrin S, Sah P, Nicoll RA (1990b) Mechanisms generating the time course of dual component excitatory synaptic currents recorded in hippocampal slices. Neuron 5:547-253.

Hofer M, Constantine-Paton M (1994) Regulation of $N$-methyl-Daspartate (NMDA) receptor function during the rearrangement of developing neuronal connections. Prog Brain Res 102:277-285.

Immelmann K (1969) Song development in the zebra finch and other estrildid finches. In: Bird vocalizations (Hinde RA, ed), pp 61-74. London: Cambridge UP.
Isaac JTR, Nicoll RA, Malenka RC (1995) Evidence for silent synapses: implications for the expression of LTP. Neuron 15:427-434.

Katz LC, Shatz CJ (1996) Synaptic activity and the construction of cortical circuits. Science 274:1133-1138.

Kew JNC, Richards JG, Mutel V, Kemp JA (1998) Developmental changes in NMDA receptor glycine affinity and ifenprodil sensitivity reveal three distinct populations of NMDA receptors in individual rat cortical neurons. J Neurosci 18:1935-1943.

Kubota M, Saito N (1991) NMDA receptors participate differentially in two different synaptic inputs in neurons of the zebra finch robust nucleus of the archistriatum in vitro. Neurosci Lett 125:107-109.

Kwon YH, Esguerra M, Sur M (1991) NMDA and non-NMDA receptors mediate visual responses of neurons in the cat's lateral geniculate nucleus. J Neurophysiol 66:414-428.

Lester RAJ, Jahr CE (1992) NMDA channel behavior depends on agonist affinity. J Neurosci 12:635-643.

Lester RAJ, Clements JD, Westbrook GL, Jahr CE (1990) Channel kinetics determine the time course of NMDA receptor-mediated synaptic currents. Nature 346:565-567.

Liao D, Hessler NA, Malinow R (1995) Activation of postsynaptically silent synapses during pairing-induced LTP in CA1 region of hippocampal slice. Nature 375:400-404.

Livingston FS, Mooney R (1997) Development of intrinsic and synaptic properties in a forebrain nucleus essential to avian song learning. J Neurosci 17:8997-9009.

Lombardino A, Nottebohm F (1993) Blockade of NMDA receptors in RA disrupts learned vocalizations in adult male zebra finches. Soc Neurosci Abstr 19:1016.

Mayer ML, Westbrook GL, Guthrie PB (1984) Voltage-dependent block by $\mathrm{Mg}^{2+}$ of NMDA responses in spinal cord neurones. Nature 309:261-263.

Monyer H, Burnashev N, Laurie DJ, Sakmann B, Seeburg PH (1994) Developmental and regional expression in the rat brain and functional properties of four NMDA receptors. Neuron 12:529-540.

Mooney R (1992) Synaptic basis for developmental plasticity in a birdsong nucleus. J Neurosci 12:2464-2477.

Mooney R, Konishi M (1991) Two distinct inputs to an avian song nucleus activate different glutamate receptor subtypes on individual neurons. Proc Natl Acad Sci USA 88:4075-4079.

Mooney R, Rao M (1994) Waiting periods versus early innervation: the development of axonal connections in the zebra finch song system. J Neurosci 14:6532-6543.

Perkel DJ (1994) Differential modulation of excitatory synaptic transmission by norepinephrine and baclofen in zebra finch nucleus RA. Soc Neurosci Abstr 20:165.

Perkel DJ (1995) Effects of neuromodulators on excitatory synaptic transmission in RA of the zebra finch. Soc Neurosci Abstr 21:960.

Perkel DJ, Nicoll RA (1993) Evidence for all-or-none regulation of neurotransmitter release: implications for long-term potentiation. J Physiol (Lond) 471:481-500.

Salt TE (1986) Mediation of thalamic sensory input by both NMDA receptors and non-NMDA receptors. Nature 322:263-265.

Scharff C, Nottebohm F (1991) A comparative study of the behavioral deficits following lesions of various parts of the zebra finch song system: implications for vocal learning. J Neurosci 11:2896-2913.

Scharfman HE, Lu SM, Guido W, Adams PR, Sherman SM (1990) $N$-methyl-D-aspartate receptors contribute to excitatory postsynaptic potentials of cat lateral geniculate neurons recorded in thalamic slices. Proc Natl Acad Sci USA 87:4548-4552.

Schoppa NE, Kinzie JM, Sahara Y, Segerson TP, Westbrook GL (1998) Dendrodendritic inhibition in the olfactory bulb is driven by NMDA receptors. J Neurosci 18:6790-6802.

Sheng M, Cummings J, Roldan LA, Jan YN, Jan LY (1994) Changing subunit composition of heteromeric NMDA receptors during development of rat cortex. Nature 368:144-147.

Shi J, Aamodt SM, Constantine-Paton M (1997) Temporal correlations between functional and molecular changes in NMDA receptors and GABA neurotransmission in the superior colliculus. J Neurosci 17:6264-6276.

Sigvardt KA, Grillner S, Wallén P, Van Dongen PA (1985) Activation of NMDA receptors elicits fictive locomotion and bistable membrane properties in the lamprey spinal cord. Brain Res 336:390-395.

Sohrabji F, Nordeen EJ, Nordeen KW (1990) Selective impairment of song learning following lesions of a forebrain nucleus in the juvenile zebra finch. Behav Neural Biol 53:51-63. 
Stark LL, Perkel DJ (1998) Developmental regulation of NMDA receptor-mediated synaptic currents in nucleus RA of the zebra finch. Soc Neurosci Abstr 24:191.

Stark LL, Perkel DJ (1999) Synaptic maturation is input-specific and occurs in two phases in nucleus RA of the zebra finch. Soc Neurosci Abstr 25:1369.

Tsumoto T, Hagihara K, Sato H, Hata Y (1987) NMDA receptors in the visual cortex of young kittens are more effective than those of adult cats. Nature 327:513-514.

Vicario DS, Cortes CM, Vates GE (1994) Development of descending projections in the zebra finch vocal control pathway. Soc Neurosci Abstr 20:164.

Wallén P, Grillner S (1987) N-methyl-D-aspartate receptor-induced, in- herent oscillatory activity in neurons active during fictive locomotion in the lamprey. J Neurosci 7:2745-2755.

White SA, Livingston FS, Mooney R (1999) Androgens modulate NMDA receptor-mediated EPSCs in the zebra finch song system. $\mathrm{J}$ Neurophysiol, in press.

Williams K, Russell SL, Shen YM, Molinoff PB (1993) Developmental switch in the expression of NMDA receptors occurs in vivo and in vitro. Neuron 10:267-278.

Wu G-Y, Malinow R, Cline HT (1996) Maturation of a central glutamatergic synapse. Science 274:972-976.

Zhong J, Gribkoff VK, Molinoff PB (1996) Use of subunit-specific antisense oligodeoxynucleotides to define developmental changes in the properties of $N$-methyl-D-aspartate receptors. Mol Pharmacol 50:631-638. 